\title{
DE VILLARREALINOS DISPLICENTES A \\ VILLARREALINOS REBELDES: RECUPERANDO LA UNIVERSIDAD PÚBLICA (2013-2016)
}

\section{From Displicent Villarrealinos To Rebel Villarrealinos: Recovering The Public University (2013-2016)}

\author{
Revista Trama \\ Volumen 9, número 2 \\ Julio - Diciembre 2020 \\ Páginas 41-89 \\ ISSN: 1659-343X \\ https://revistas.tec.ac.cr/trama
}

Alvaro Liendo Moscoso ${ }^{1}$ / Daniel Caravedo Ayasca ${ }^{\mathbf{2}}$ / Steffany Ruiz Lozada ${ }^{3}$

Fecha de recepción: 24 de abril, 2020

Fecha de aprobación: 11 de setiembre, 2020

Liendo, A., Caravedo, D. y Ruiz, S. (2020). De villarrealinos displicentes a villarrealinos rebeldes: recuperando la universidad pública (2013-2016). Trama, Revista de ciencias sociales y humanidades, Volumen 9, (2), Julio-Diciembre, págs. 41-89.

DOI: https://doi.org/10.18845/tramarcsh.v9i2.5568

1. Bachiller en Sociología, Universidad Nacional Federico Villarreal. Lima, Perú. Graduado del Diplomado en Gestión del Cambio y Desarrollo Territorial por la Universidad Antonio Ruiz de Montoya en convenio con Escuela para el Desarrollo.

Correo electrónico: aliendom12@hotmail.com ORCID: 0000-0002-4745-2042

2. Bachiller en Sociología, Universidad Nacional Federico Villarreal. Lima, Perú. Comunicador audiovisual. Egresado del Instituto Superior Tecnológico Público Diseño y Comunicación.

3. Egresada de Sociología. Universidad Nacional Federico Villarreal. Lima, Perú. 


\section{RESUMEN}

En 2014, la ley de reforma universitaria $\mathrm{N}^{\circ}$ 30220 era aprobada por el Congreso de la República de Perú; en un contexto convulsionado de oposición a los nuevos parámetros suprainstitucionales, que los grupos de poder universitarios creían, vulneraban su autonomía. El movimiento estudiantil villarrealino, con sus limitaciones y tensiones, asume el liderazgo en la capital durante este periodo. Bajo una estructura de liberalización del mercado educativo y desmovilización heredada de los años noventa es que nos preguntamos ¿Qué alcances y limitaciones presentó la acción colectiva del movimiento estudiantil en Villarreal durante los años 2013 al 2016? El objetivo de este artículo entonces será aproximarnos y determinarlo. Para este trabajo aplicamos la investigación participante y la sistematización retrospectiva de los hechos como métodos de investigación; con el fin de reconstruir la experiencia y orientar intervenciones del movimiento. Para ello hemos analizado fuentes escritas y orales de los estudiantes y egresados involucrados. Por otro lado, este es un ensayo por analizar los matices entre los diversos enfoques teóricos de los movimientos sociales, como vías eventualmente contradictorias, aplicada a este caso y enfocado en sumergirse en la subjetividad política de quienes buscan el cambio. Este proceso de conquistas paulatinas de los estudiantes debieran servir para redirigir sus esfuerzos hacia el gobierno universitario con la misma tenacidad que han destinado para la organización de base con el fin último de quebrar la hegemonía de los intereses partidarios ocultos visibilizados en tiempo de crisis; promoviendo iniciativas legislativas y dotándolas de mecanismos de mayor alcance democrático.

Palabras clave: democracia universitaria; au-tonomía; movimientos sociales; subjetividad política.

\section{ABSTRACT}

In 2014, the university reform law $N^{\circ} 30220$ was approved by the Congress of the Republic of Peru; in a convulsed context of opposition to the new supra-institutional parameters, which the university power groups believed, violated their autonomy. The Villarrealino student movement, with its limitations and tensions, assumed leadership in the capital during this period. Under a structure of liberalization of the educational market and demobilization inherited from the nineties, we ask ourselves: what scope and limitations did the collective action of the student movement in Villarreal present during the years 2013 to 2016 ? The objective of this article then will be to approximate and determine it. For this work we apply participant research and retrospective systematization of the facts as research methods; in order to reconstruct the experience and guide interventions of the movement. For this we have analyzed written and oral sources of the students and graduates involved. On the other hand, this is an essay to analyze the nuances between the various theoretical approaches of social movements, as eventually contradictory paths, applied to this case and focused on immersing oneself in the political subjectivity of those who seek change. This process of gradual conquests of the students should serve to redirect their efforts towards the university government with the same tenacity that they have destined for the grassroots organization with the ultimate aim of breaking the hegemony of the hidden party interests made visible in times of crisis; promoting legislative initiatives and providing them with mechanisms of greater democratic scope.

Key words: university democracy; autonomy; social movement; political subjectivity. 


\section{INTRODUCCIÓN}

La crisis de la universidad pública por vía de la descapitalización es un fenómeno global, aunque sean significativamente diferentes sus consecuencias en el centro, en la periferia o en la semi-periferia del sistema global. En los países centrales la situación es diferente (Santos, 2006. p. 26).

En la periferia, donde la búsqueda de ingresos alternativos en el mercado o fuera de él es virtualmente imposible, la crisis logra proporciones catastróficas. Obviamente que los males venían de atrás, pero se agravaron mucho más en la última década con la crisis financiera del Estado y los programas de ajuste estructural (Santos, 2006. p. 27).

La muy significativa expansión de la matrícula, a partir de los años 90, y los procesos de desfinanciamiento fueron elementos centrales para la privatización de la tercera ola, con universidades públicas sin recursos suficientes, sistemas de selección que se reforzaban para contener los ingresos y universidades privadas con mayor facilidad para el acceso (Saforcada, Atairo, Trotta, Rodríguez Golisano, 2019)

Sobre los efectos del neoliberalismo en la educación universitaria Santos (2006) menciona:

La pérdida de prioridad de la universidad pública en las políticas públicas del Estado fue, ante todo, el resultado de la pérdida general de prioridad de las políticas sociales (educación, salud, seguridad social) inducida por el modelo de desarrollo económico conocido como neoliberalismo o globalización neoliberal, que se impuso internacionalmente a partir de la década de los 80. En la universidad pública esto significó, que las debilidades institucionales antes identificadas -que no eran pocas - en vez de servir para un amplio programa político pedagógico de reforma de la universidad pública, fueron declaradas insuperables y utilizadas para justificar la apertura generalizada del bien público universitario para la explotación comercial.

La progresión desde el año 2010 hasta la información más reciente, es posible observar que esta tendencia de crecimiento relativo y absoluto del sector privado se sostiene en la mayor parte de los países de América Latina (Saforcada, Atairo, Trotta y Rodríguez Golisano, 2019). 
Tabla 1: Porcentaje de estudiantes en la educación superior por sector de gestión en América Latiana y el Caribe. 2010-2016. ${ }^{4}$
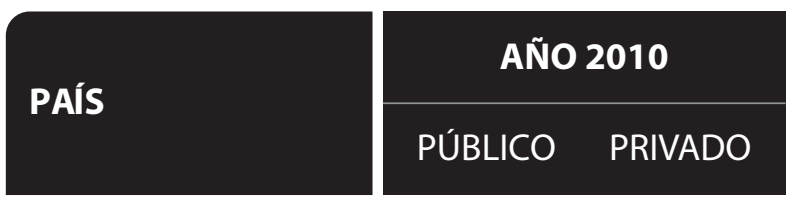

Cuba

Bolivia

Argentina

México

Panamá

Honduras

Ecuador

Colombia

Costa Rica

América Latina

República Dominicana

El Salvador

Puerto Rico

Perú

Brasil

Chile

$60 \%$

$62 \%$

$55 \%$

$49 \%$

$48 \%$

$49 \%$

$33 \%$

$27 \%$

$33 \%$

$29 \%$

$\begin{array}{ll}100 \% & 0 \% \\ 83 \% & 17 \%\end{array}$

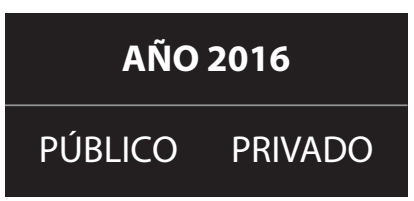

$100 \% \quad 0 \%$

$86 \% \quad 14 \%$

$18 \%$

Fuente: Saforcada, Fernanda
$78 \%$

$21 \%$

$21 \%$

$32 \%$

$36 \%$

$40 \%$ $38 \%$

$45 \%$

$51 \%$

$52 \%$

$51 \%$

$77 \%$

$73 \%$

$63 \%$

$72 \%$

$82 \%$

$14 \%$

$22 \%$

$75 \%$

$67 \%$

$67 \%$

$64 \%$

$55 \%$

$50 \%$

$49 \%$

$45 \%$

$41 \%$

$30 \%$

$30 \%$

$28 \%$

$27 \%$

$15 \%$

Rodríguez Golisano,Aldana (2019).
DIFERENCIA

PORCENTUAL

2016/2017

$0 \%$

$-3 \%$

$1 \%$

$4 \%$

$1 \%$

$-3 \%$

$-4 \%$

$7 \%$

$5 \%$

$0 \%$

$3 \%$

$8 \%$

$-7 \%$

$-3 \%$

$9 \%$

$1 \%$

$3 \%$

4. Nota: En Brasil, Costa Rica y Ecuador por faltante de datos para 2010, se registra el dato del año 2011. En Ecuador para 2016 se repite año 2015. 
La expresión de tal liberalización de la educación superior en el mercado empezó a agudizarse con el DL 882 emitido por el gobierno de Alberto Fujimori. Tal norma promueve la iniciativa privada en educación, amparada en el rol subsidiario del Estado que se esgrime en la constitución política del Perú. Bajo esta estructura económica es que el movimiento estudiantil villarrealino planea su accionar.

Bajo esta estructura de desfinanciamiento y liberalización del mercado educativo nos preguntamos ¿Qué alcances y limitaciones presenta el movimiento estudiantil y en específico en Villarreal durante el debate, aprobación y adecuación de la nueva ley universitaria? Para ello, el objetivo de este artículo es analizar los alcances y limitaciones de la acción colectiva en Villarreal entre los años 2013-2016. Para ello buscaremos comprender los objetivos, formas de organización y acciones de la organización de la acción colectiva en el contexto de aprobación y aplicación de la ley universitaria $\mathrm{N}^{\circ} 30220$. Lo habitual, cuando se habla de reformas en el ámbito universitario es recurrir a movimientos sociales interviniendo en procesos de democratización de la educación pública. Sin embargo, en este caso, creemos que es necesario evaluar de parte los efectos inmediatos que tuvo la aprobación y aplicación de la reforma universitaria aplicada desde el pleno del congreso, como parte de un proceso episódico y dinámico. Tales evidencias, podrían ser útiles para contribuir a comprender empíricamente, la complejidad de las relaciones entre estado y sociedad en el ámbito de la educación universitaria. 


\section{METODOLOGÍA}

Para este trabajo aplicamos la sistematización retrospectiva ${ }^{5}$ como método de investigación con el fin de rescatar y reconstruir la experiencia y orientar intervenciones del movimiento estudiantil. ${ }^{6}$ Oscar Jara (2014) la define cómo:

Aquella interpretación crítica de una o varias experiencias que, a partir de su ordenamiento y reconstrucción, descubre o explicita la lógica y el sentido del proceso vivido en ellas: los diversos factores que intervinieron, cómo se relacionaron entre sí y por qué lo hicieron de ese modo. (p.99)

Cómo estrategia hemos adoptado la investigación acciónparticipante al considerar, cómo Santos (2006), que esta consiste: "en la definición y ejecución participativa de proyectos de investigación involucrando a las comunidades y a las organizaciones sociales populares, en la medida que los problemas cuya solución puede beneficiar los resultados de la investigación." (p. 67).

Por lo tanto, un objetivo secundario de este trabajo es facilitar la contemplación de las oportunidades y debilidades de la acción colectiva y contribuir, a través de una mirada crítica, a fortalecer su estructura en la búsqueda de transformaciones hacia afuera y dentro de la universidad peruana; haciendo el intento de superar lo que Edgar Morín (1984) llamara: "Principio de disyunción absoluta entre el objeto y el sujeto que lo percibe/concibe. La verificación por observadores/experimentadores diversos basta, no sólo para alcanzar la objetividad, sino para excluir al sujeto cognoscente" (p. 359).

Establecimos dos ejes de sistematización para el acopio cronológico y ordenado de la información, el eje: aprobación de la ley universitaria y el eje: adecuación a la ley universitaria. El hilo narrativo ${ }^{7}$ es desarrollado bajo esta estructura tomando en cuenta observaciones de campo, documentos oficiales, prensa escrita, televisiva y los testimonios que los actores claves nos han proporcionado, utilizando guías de entrevista abiertas y semiestructuradas. Para el muestreo cualitativo primero nos anticipamos a dos tipos de perfiles. Incluimos una distribución de

5. Retrospectiva al elaborarse cuando la experiencia ha culminado.

6. Cabe acotar que este también es un esfuerzo que busca contribuir a registrar lo ocurrido y que no busca ser una versión culminada de los hechos.

7. Hilo conductor que atraviesa la(s) experiencia(s), referida a los aspectos centrales que nos interesan sistematizar en este momento (Jara, 2014). 
ciertos rasgos (Flick, 2007. p. 48). Informantes con participación en la situación inicial/media de la experiencia o informantes con experiencia de participación en la situación final, de diversas carreras profesionales $y$, en la medida de la voluntad para ofrecer el testimonios de los y las entrevistados/as, respetando las cuotas de género.

Asimismo, aplicamos grupos de discusión y entrevistas individuales. Sobre estos primeros, respetamos la homogeneidad con respecto a la situación o fase de la experiencia en que sus integrantes participaron, pero de carreras profesionales heterogéneas por constituir grupos de participación distintos con el fin de contrastar sus testimonios y que lleguen a conclusiones colectivas (Flick, 2015). Contamos con su autorización, vía correo electrónico, para que los fragmentos de las transcripciones utilizadas en este documento sean publicados.

Queremos hacer hincapié en que no pretendemos plasmar una visión excesivamente pegada a lo que dice la ley, tampoco necesariamente hacer un análisis exhaustivo de esta, no es materia de nuestra especialidad. Pero sí señalar, en base a la impersonalidad que formula el espíritu de las leyes, la utilidad que esta ofrece para resolver controversias cuando se trata de sucesiones en cargos públicos - administrativos. Esperamos, en otra oportunidad, hacer un análisis más exhaustivo sobre otros procesos universitarios que por supuesto merecen ser difundidos en la comunidad universitaria y sociedad en su conjunto.

Agradecemos especialmente a las siguientes personas: a Juber Cotrina y Betsabeth Zuzunaga por colaborar con la aplicación del plan piloto, así como a cada uno de los entrevistados del plan final. A Rogelio Scoth por sus observaciones de naturaleza metodológica y a Cruz Silva por su dedicación a la defensa legal de las y los estudiantes que fueran perseguidos judicialmente. 


\section{MULTIDIMENSIONALIDAD, SUBALTERNIDAD Y SUBJETIVIDAD POLÍTICA}

Al tratarse, este de un análisis empírico que busca comprender los alcances y limitaciones del movimiento estudiantil durante los años 2013 - 2016; es menester caracterizarlo en base a sus metas y estructura (Rashke, 1994), teniendo en cuenta que, como señala (Rashke, 1994): "No son simples «medios:» del cambio social; ni la pasiva expresión de tendencias sociales de cambio, sino que; en mayor medida; son actores que se involucran activamente en el curso de las cosas con el fin de influir sobre ese desarrollo (p. 123). Entonces ¿Por qué involucrarse progresiva y masivamente? Además, existe un conocimiento fragmentado de los diversos enfoques de caracterización de los movimientos sociales. Para Garza (2011) estos serían: "los enfoques clásicos, el de la movilización de recursos, el de los nuevos movimientos sociales y finalmente el de los enfoques actuales" (p. 107).

No buscamos encasillarnos en un único enfoque, más bien tomar elementos de cada uno de ellos en base al análisis empírico. Garza (2011) propone: "estudiar a los MS [movimientos sociales] desde varias perspectivas, enfatizando el conflicto a su interior, expresado en la competencia por imponer una visión general del conflicto, pues sólo desde ella se podrán comprender las formas de organización y acción"(p.138).

Entonces, no habría signos de pureza en tal caracterización. Fernando Calderón y Elizabeth Jelin (s/f) citados por Santos (2001) dicen: "en contraste con lo que pasa en los países centrales, una de las características propias de América Latina es que no hay movimientos sociales puros o claramente definidos, dadas la multidimensionalidad, no solamente de las relaciones sociales sino también de los propios sentidos de la acción colectiva" (p. 180-181).

El de Villarreal es un movimiento dinámico al que ingresan nuevas tendencias, renovando formas de organización institucionales por las no institucionalizadas y radicalizando sus medidas de fuerza en momentos en lo que ve perder su poder de negociación colectiva. Por lo tanto, creemos que es un movimiento de gestación interna adherido a uno mayor, local y nacional, sobre el cual, presumimos, tiene características definidas: participación gremial, sucesos violentos, tendencias redistributivas de recursos públicos; pero que no terminan de cuajar con autonomía de las iniciativas estatales como un actor colectivo insertado en las relaciones de poder; lo cual no nos permita determinar una meta unitaria o final, aunque si este presente en algunos de sus actores. Lo cual creemos está relacionado de manera determinante, a la formación de la subjetividad política de sus individuos. Es decir, como señala 
Modonessi (2010) citando a Thompson (1981): "la experiencia como clave de análisis de los procesos de formación subjetiva" (p.19). Suele ser este proceso el que desconecta a los actores de permanente acción colectiva con los que se insubordinan en crisis institucionales, para el caso las de los años 2010 y 2016.

Si para Raschke (1994) movimiento social es:

un actor colectivo movilizador que, con cierta continuidad y sobre las bases de una alta integración simbólica y una escasa especificación de su papel, persigue una meta consistente en llevar a cabo, evitar o anular cambios sociales fundamentales, utilizando para ello formas organizativas y de acción variables (p.124).

¿Cuándo pasa de ser mera acción colectiva a movimiento? Es de resaltar que el objetivo primigenio del movimiento fue el archivamiento del proyecto de ley, adaptándose luego a la adecuación de esta en Villarreal y causando un efecto movilizador aun mayor. Bajo esta premisa, ¿Siempre lo fue? Y si es así ¿Por qué en la práctica se reformula el objetivo con el transcurrir del tiempo? ¿Cuáles fueron los momentos divergentes y cuáles los unificantes? ¿Qué actores se unifican?

Por otro lado, la subalternidad, como presupuesto teórico, nos resulta a la vez una categoría útil para analizar transversalmente a los actores de la acción colectiva. Existe mucha similitud en la definición entre Movimientos Sociales y Clases subalternas para conceptos de análisis o como mencionara Modonessi (2010): "elementos distintivos: pluralidad, disgregación, carácter episódico de su actuar, débil tendencia hacia la unificación" (p.32). Bajo la hipótesis que plantea Baratta citado por Modonesi (2010): [las clases subalternas] se distinguen de las clases productivas. Por lo tanto sería un concepto más amplio. (Modonesi, 2010). Sin embargo, al ser la experiencia de subordinación vital para formación de las subjetividades políticas, existe una interpretación más compleja que rechaza: el dualismo maniqueo que pretenda escindir a los sujetos reales a partir de la separación entre rebeldía y sumisión como momentos separados (Modonesi, 2010; p. 34). Lo que nos hace preguntarnos ¿Por qué se dio este salto de la displicencia (desmovilización) en el contexto de debate al de rebeldía (movilización) durante la adecuación de la ley?

Al respecto de los elementos de "novedad" en este movimiento social, es usual no detentar un enfoque que no involucre la teoría de los NMS. Entre las tendencias comunes que señala Raul Zibechi (2007) 
para América Latina, los más presentes podrían tratarse de: la búsqueda de autonomía, tanto de los Estados como de los partidos políticos y la autogestión, aunque, como dinámica en distintas etapas y no siendo este un movimiento territorializado como preferiría Zibechi. ¿Autonomía? Pues del aprismo como partido hegemónico en la administración de Villarreal, contra quien también se dirige la protesta y a veces de las relaciones políticas formales e informales que administran el estado y sus instituciones, dependiendo de si se contraponen o no a los intereses del movimiento.

Más cercano a una autonomía relativa, al inicio como principio cuando se busca archivar la ley, al final como táctica cuando se busca adecuarla. No como esencia, método o forma de lucha (Modonesi, 2010.p.101) 


\section{ANTECEDENTES}

Las autoridades de la Universidad Nacional Federico Villarreal ${ }^{\mathbf{8}}$ tienen en 2010 el más reciente antecedente con respecto a la ingobernabilidad a la luz de la ley $N^{\circ} 23733$. Según la Asamblea Nacional De Rectores (2010): "violando el artículo $39^{\circ}$ de la Ley Universitaria, en el que el Consejo Universitario de la UNFV, presidido por el Rector, interfiere el proceso electoral, lo cual constituye causal de grave irregularidad que obstaculiza la elección para renovación de los representantes docentes y estudiantiles y la conformación legal de los órganos de gobierno" (p.1). En este sentido, la Asamblea Nacional de Rectores (2010) resuelve: "declarar en situación de ingobernabilidad a la Universidad Nacional Federico Villarreal y suspender en sus funciones a los profesores que a la fecha vienen ejerciendo los cargos de Rector y Vicerrectores Académico y Administrativo, respectivamente [y] conformar una Comisión de Orden y Gestión, (...) por el plazo de 180 días" (p.3).

Bajoeseescenario se formala Coordinadora Democrática Estudiantil (COODE) con el propósito de darle organización gremial centralizada a los problemas comunes de los estudiantes a falta de una federación que los aglutine. En sus inicios estaba integrada por organizaciones estudiantiles de oposición al gobierno universitario de distintas especialidades. Entre ellas, Vanguardia Villarrealina en la Facultad de Derecho y Ciencias Políticas y que desde entonces fuera elegida para cumplir, por cuatro años consecutivos, labores de representación ante el consejo de facultad; Rumi Maqui ${ }^{9}$ en la Facultad de Educación; la agrupación, Conciencia Estudiantil en la Facultad de Ciencias Sociales, y desde 2013, en su lugar, Sociales Independiente, quienes también cumplieron esta misma tarea. Ciq'antu ${ }^{10}$ en la Facultad de Humanidades; todas estas especialidades ubicadas en el Local Central del cercado de Lima y Transparencia de la Facultad de Psicología en el local conocido como Anexo $8{ }^{\mathbf{1 1}}$.

8. Villarreal fue fundada en 1963, siendo antes, una filial en Lima de la Universidad Particular Comunal del Centro, gracias a los esfuerzos de las comunidades campesinas del Valle del Mantaro (CVR, 2003 a) y sus principales gestores, los entonces políticos e intelectuales de filiación aprista, Ramiro Prialé, quien fuera secretario general del partido durante 1945 y 1965, José Véliz L., César Solís y el destacado geógrafo Javier Pulgar V., su primer rector en los cincuentas. (Congreso de la República, s.f.; INFOGOB, 2018 a; INFOGOB b; PUCP, 1999; UNFV, 2017 a)

9. Mano de Piedra del quechua al castellano.

10. Flor de la cantuta del quechua al castellano.

11. La universidad no cuenta con un campus o ciudad universitaria. En su lugar, las carreras profesionales que ofrece, cuentan con varios predios o anexos distribuidos en algunos distritos de Lima Metropolitana. 


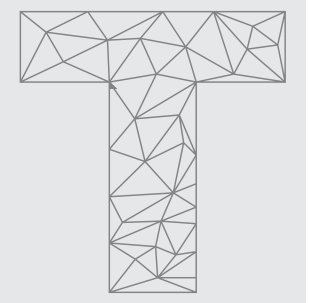

Figura 1: La Universidad Villarreal y sus predios.

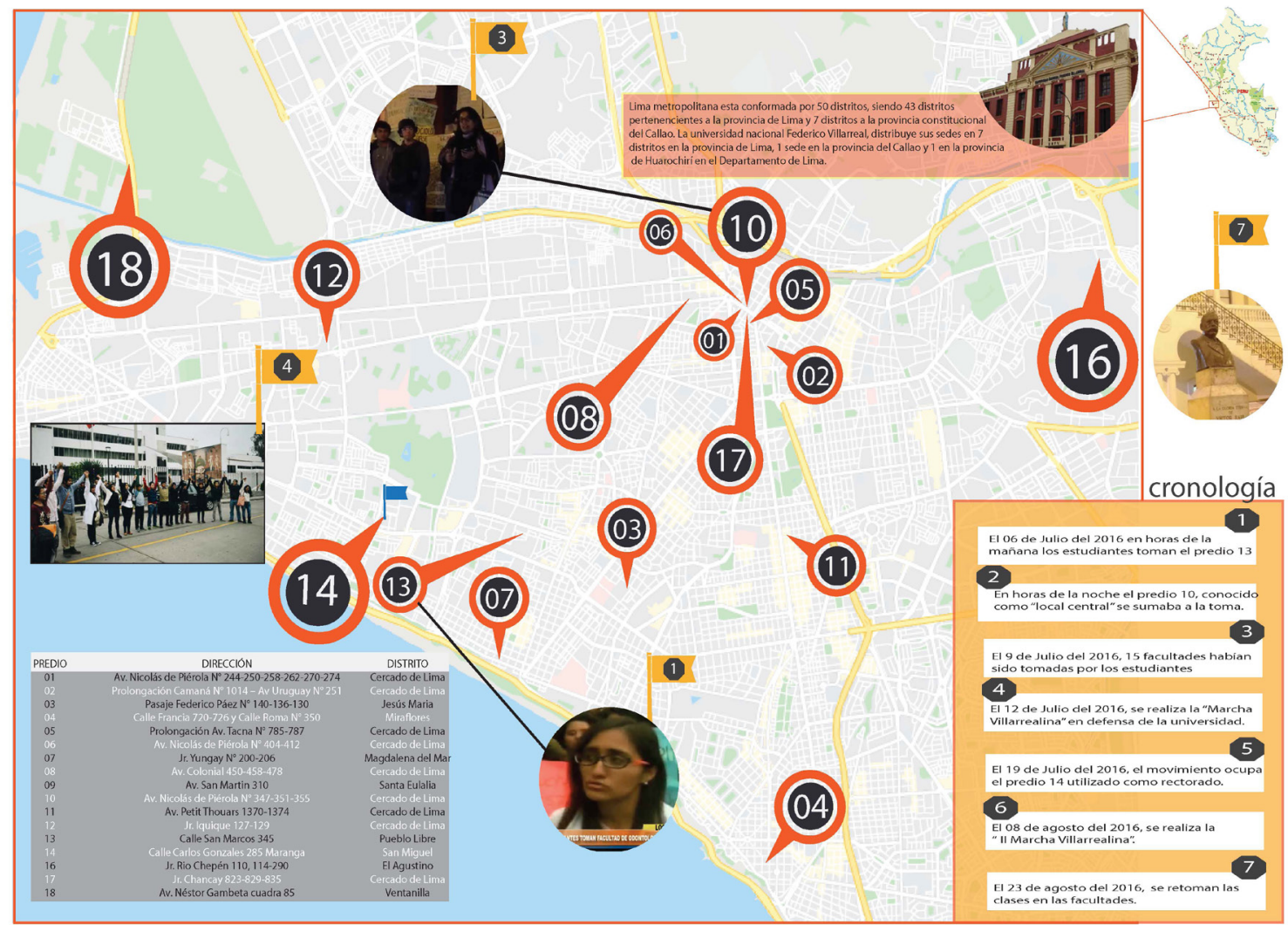

Fuente: elaboración propia.

Para efectos prácticos en adelante los llamaremos Grupos Estudiantiles en el Cogobierno ${ }^{\mathbf{1 2}}$.

John Lapa (2017), egresado de la Facultad de Administración y representante de la coordinadora durante el año 2013 recuerda los hechos así:

La organización del movimiento estudiantil inicia alrededor del año 2009, 2010 donde estudiantes del local central con distintos colectivos logran organizar [la] Coordinadora Democrática Estudiantil,

12. Es decir, en el cogobierno de sus respectivas facultades: Vanguardia en Derecho, Sociales Independiente en Sociales, Rumi Maqui en Educación y Transparencia en Psicología. 
un espacio de debate, de consolidación de propuestas de algunas ideas de constitución de los gremios en la universidad.

Se identifican intereses comunes, se protesta, se organizan. Hay un primera paso de la acción colectiva al movimiento.

Aunque nuestro espacio temporal de análisis es entre los años 2013 - 2016, dado que partimos de la premisa en que los movimientos sociales son dinámicos, ese episodio en 2010 resulta un antecedente para presumir que en Villarreal las crisis institucionales aglutinan el movimiento y diluido este, se forman organizaciones estructuradas e institucionales de largo aliento, por ejemplo, en los órganos de cogobierno a nivel de facultad. Principalmente ante sucesos de ingobernabilidad y como respuesta a la privación de necesidades funcionales. Melucci (1998) lo explica como: "cuando la realización de las expectativas es inferior a la satisfacción de las necesidades, es sobre la base de un grupo de referencia que tiene una privación y por ello una disponibilidad a la acción conflictual" (p. 33). Aquí podemos hallar la formación subjetiva de los primeros actores del movimiento en cuestión y que alcanzará su máximo despliegue en años siguientes. 
Sobre la hegemonía de la Alianza Popular Revolucionaria Americana $(\text { APRA })^{13}$ en Villarreal John Lapa (2017), vocero de la Coordinadora Democrática Estudiantil en el año 2013 nos cuenta:

La dictadura que manejaba el APRA dentro de las aulas, dentro de los auditorios y dentro del patio mismo era muy fuerte, lo que empujaba al movimiento estudiantil a tener la necesidad de organizarse. Entonces, en ese sentido, buscando las reivindicaciones que todos queremos: mejores docentes, comedor universitario, tener un campus, tener el derecho a criticar, a aprender más y a debatir [...] nosotros decidimos no estar a favor del APRA para crear una posición, una tendencia que busque reivindicaciones y que critique el estatus que había en la universidad.

Cabe recordar que hasta los años sesenta el APRA tenía influencia en prácticamente todas las universidades, sin embargo, a partir de los años setenta esta había quedado bastante reducida frente a las diversas corrientes de la izquierda marxista. El aprismo ${ }^{\mathbf{1 4}}$ sólo mantenía el control en la Universidad Federico Villarreal (Reyna, 2000, p. 18; CIDOB, 2016). Desde entonces es tradicionalmente conocida en el imaginario popular capitalino como bastión aprista, producto de una cuasi secular identidad institucional afín a la doctrina partidaria y la formación de una red de alianzas en el sistema universitario. Sus más destacados militantes han fungido de funcionarios y docentes en sus claustros ${ }^{15}$, pero también en instancias suprauniversitarias bajo un sistema de promoción desregulada

13. En palabras de su fundador, Víctor Raúl Haya de la Torre es un: "frente único internacional de trabajadores manuales e intelectuales (obreros, estudiantes, campesinos, intelectuales, etcétera), con un programa común de acción política" (p.). Fundado en México en 1924. El historiador Nelson Manrique (2009) postula que: "para efectos prácticos, luego de la fundación del Partido Aprista Peruano, en 1931, la Alianza Popular Revolucionaria Americana, una organización supranacional, desapareció. Lo que quedó en adelante fue el partido nacional conocido popularmente como el Apra" (p.18).

14. Referente al Partido Aprista Peruano como corriente política en el Perú.

15. Han sido docentes $\mathrm{y} / \mathrm{o}$ funcionarios en la universidad la ex ministra de educación y del interior, Mercedes Cabanillas (INFOGOB, 2018 d; Oficio $\quad N^{\circ}$ 231-OCRNICT-UNFV, 2014; UNFV, 2017 b), el ex rector Orestes Rodríguez Campos, asesinado cobardemente por Sendero Luminoso (CVR,2003 b; INFOGOB, 2018 e), José María Viaña, ex vicepresidente de la ANR, ex presidente del Consejo Nacional de Evaluación, y Acreditación Universitaria - CONEAU y ex vocal del Consejo Directivo Fundador de la Asociación de Universidades del Perú - ASUP (ASUP, 2018), Nancy Oliveros Pacheco, ex vicerrectora y ex miembro del CONEAU (SINEACE, 2010) y el actual rector Juan Oswaldo Alfaro Bernedo, presidente del Consejo Regional Interuniversitario de Lima y Callao de la ASUP (ASUP, 2017 a), integrante de la Asamblea Estatutaria en Villarreal en 2016 y afiliado también al partido de la estrella.(INFOGOB, 2018 f). 
de la iniciativa privada en educación y de expansión universitaria no necesariamente relacionada con el acceso masivo de todos los peruanos (Casas Frank, 2012, p. 154).

Desde el ex presidente Alan García Pérez (CIDOB, 2016; INFOGOB ${ }^{\mathbf{1 6}}$, 2018 c), quien en el meeting por el día de la Fraternidad Aprista del 2014, manifestará públicamente que de detentar nuevamente la máxima magistratura del Estado, derogaría la nueva ley universitaria:

[...];Cómo es posible que seiscientos años después, intente aprobarse una ley que crea una superintendencia casi militar sobre todas las universidades, para decir qué hay que estudiar, qué facultades se pueden crear! ¡Eso viola y desnaturaliza el principio central de la libertad del pensamiento y nosotros desde aquí advertimos! ¡Con esa mayoría precaria que ya no tiene sustento en las calles y los hogares, aprueben lo que sea, pero en el año 2016 las fuerzas democráticas terminarán contrael atentado en contra de la autonomía universitaria! (Corresponsales.pe, 2014).

Al respecto del sistema desregulado de educación universitaria o, como lo Ilama Ricardo Cuenca(2015): "la tensión producida en el espacio creado entre la democratización del acceso y la precarización del servicio"(p.10)., Cuenca (2015) sostiene:

Fueron tres las hipótesis que estuvieron detrás de la decisión de liberalizarla oferta educativa universitaria. La primera sostuvo que con la participación privada se conseguiría ampliar la oferta y la cobertura universitarias. La segunda argumentó que, como consecuencia de la primera, el acceso a los estudios superiores se democratizaría; es decir, más jóvenes de todos los estratos económicos estudiarían en la universidad. Finalmente, se supuso que el mercado sería un regulador efectivo de la calidad de este servicio, mediante el cual la competencia dejaría fuera a las universidades de mala calidad (p.11).

La Coordinadora Democrática Estudiantil, suscribe entonces una posición en contra de la mercantilización de la educación universitaria y la utilización política del claustro para fines partidarios hegemónicos, en específico, Villarreal, al que John Lapa, ex vocero de la COODE dentro y fuera de la universidad, adjetiva como: "dictadura". Esta oposición frontal

16. Página web oficial del Jurado Nacional de Elecciones que custodia el registro de militantes inscritos en organizaciones políticas del Perú. 
contra la mercantilización de la educación, es más común verla expresada en organizaciones herederas del clasismo y que disputó, durante gran parte del siglo XX, la dirección del movimiento sindical en el Perú; con un repertorio definido de objetivos, formas de organización, acción y discurso. Flores Galindo (2007) dice:

[El clasismo] se propaló por otros sectores, dejando de ser una ideología y convirtiéndose en una manera de encarar, aparte de las reivindicaciones inmediatas, el conjunto de las relaciones entre ciudadanos y Estado. "Clasistas" se auto-denominaron los maestros, los empleados bancarios, los burócratas, los escolares, los vendedores ambulantes ( $p .457)$.

Esta tendencia y facciones políticas son parte neurálgica de la organización expresadas en federaciones universitarias en todo el Perú. Más adelante desarrollaremos más esta cuestión. 


\section{LA LEY UNIVERSITARIA EN DEBATE (2013): PRIMEROS ACTORES Y DISCURSOS EN LA PROTESTA ESTUDIANTIL}

Durante el quinquenio 2011- 2016, la Comisión de Educación del Congreso de la República, presidida por el entonces congresista Daniel Mora, elabora los primeros pre-dictámenes que, sumada a algunas iniciativas legislativas particulares, apertura con éxito el debate ante la opinión pública y establece en la agenda nacional la necesidad de una reforma de la educación superior. Entre ellas, en el año 2012, la de un grupo parlamentario multipartidario ${ }^{\mathbf{1 7}}$ que pretendía modificar la ley $N^{\circ} 23733$ para la elección universal de autoridades y su revocatoria, concomitante a la propuesta de las organizaciones gremiales de estudiantes en la Universidad Nacional San Cristóbal de Huamanga y la Universidad Nacional Santiago Antúnez de Mayolo, quienes venían desarrollando procesos plebiscitarios para conducir la elección universal, personal, directa y secreta de representantes en el cogobierno. En el mismo año, también fue promulgada la ley $N^{\circ} 29971$ que establece la moratoria de creación de universidades públicas y privadas por un plazo de cinco años ante la necesidad de una nueva ley universitaria ${ }^{\mathbf{1 8}}$. Esta voluntad por reformar el marco normativo hizo manifiesto el interés, casi inédito del poder legislativo, por modernizar a través de una nueva ley los principios originarios de la universidad como: la autonomía para gobernarse; los fines, como la investigación para el desarrollo nacional y la estructura institucional del sistema universitario, que comprometen la administración de la calidad de la educación, sus recursos financieros y humanos (Congreso de la República, 2014).

Es así que, el debate tuvo mayor algidez cuando se empezó a evaluar al entonces máximo entre rector, la ANR y su trabajo de supervisión en el funcionamiento de las universidades del Perú, poniendo en tela de juicio los efectos reales de la autonomía universitaria en la educación. Dos fueron los ejes ${ }^{\mathbf{1 9}}$ más importantes que empleó el ex congresista Daniel Mora para elaborar críticas profundas al sistema universitario vigente: los constantes indicios de corrupción y las escasas garantías para asegurar condiciones básicas de calidad. Sobre el primer eje fue mediático el caso del rector de la Universidad Inca Garcilaso de la Vega, Luis Cervantes Liñán (2004 - 2019), cuando se devela que recibiera por

17. Fueron los proyectos de ley 154, 368 y 486 del grupo parlamentario: Gana Perú por iniciativa de los ex-congresistas Teófilo Gamarra, Rubén Condori y Jorge Rimarachín.

18. Fueron los proyectos de ley 807 y 998 de los grupos parlamentarios: Solidaridad Nacional, por iniciativa del ex-congresista Vicente Zeballos y Gana Perú, por iniciativa del ex-congresista Rubén Condori, respectivamente.

19. Definimos como ejes a los puntos críticos sobre los que el ex congresista esgrimió fundamentos para la defensa de la nueva ley universitaria y que esta contribuiría a resolver. 
múltiples honorarios la suma de S/. 2174156.34 mensuales $^{\mathbf{2 0}}$ (AFP, 2014) al ocupar este y otros cargos en la misma institución. Mora acusa a la ANR de: "proteger a Cervantes en vez de investigarlo" (RPP, 2014). Sobre el segundo eje, también se hizo público a través de reportajes televisivos de horario estelar, la condición de universidades públicas con colosales ingresos directos por impuestos de renta minera y universidades privadas exoneradas de tributar impuesto a la renta, con una inadecuada infraestructura para ofrecer educación de calidad, las cuales fueron catalogadas por el congresista Mora cómo: "universidades chicha" (El Comercio, 2014).

Por otro lado, durante este periodo, un proceso poco evidente iba aconteciendo: la reorganización del movimiento estudiantil en base a una agenda propia de alcance nacional. En esta se encontraría la Federación de Estudiantes del Perú (FEP), federaciones universitarias, centros federados, agrupaciones estudiantiles y políticas con una identidad y experiencia heredera principalmente del clasismo como forma de encarar el conjunto de las relaciones entre ciudadanos y Estado (Flores Galindo, 2007 a p. 457), sumado a lo que la Comisión de la Verdad y Reconciliación (2003) catalogaría como:

Al proceso de intervención de las universidades de la dictadura fujimorista en los noventas y la violencia política, que incentivó la formación de un prejuicio contra miles de universitarios que por pertenecer a una universidad nacional, eran usualmente detenidos como sospechosos de subversión y las universidades intervenidas académica y administrativamente por los gobiernos de turno" (p. 233).

Es así que el conglomerado de organizaciones estudiantiles se alerta y reacciona ante la posibilidad de una reforma legal de la educación universitaria, identificando en este contexto un espacio de encuentro, discusión y disputa política por dirigir al movimiento, elevando como objetivos inmediatos. La inclusión de sus representantes en el debate parlamentario, el archivamiento de los pre dictámenes y la ley universitaria una vez que esta fue aprobada, por considerar que le daba continuidad a la asfixia del financiamiento de la universidad pública, que era privatizadora, mercantilista y que además criminaliza la protesta y participación estudiantil (Comité Nacional de Lucha, 2014).

20. Aproximadamente 630 mil dólares americanos mensualmente. 
John Lapa (2017) recuerda:

El estudiantado se alerta, la UNFV es una de las primeras en poner eso en evidencia. Nos organizamos. Hubo un encuentro de estudiantes en la ciudad de Huancayo en marzo que convocaron a la movilización del 4 de julio y en esa convocatoria se plante la constitución del Comité Nacional de Lucha (CNL) del movimiento estudiantil [...].

El 4 de julio del 2013 fue el día central en que un número significativo de estudiantes de todo el Perú salen a las calles en contra de la aprobación de la nueva ley donde también las organizaciones estudiantiles de Villarreal participan movilizándose junto a otras universidades de la capital, rumbo al hemiciclo, para exigir ser escuchados. 10 personas fueron detenidas junto a manifestantes de otra marcha que la Central General de Trabajadores del Perú (CGTP), había convocado con el fin de lograr el archivamiento de otra ley que también pretendía reformar, en otros asuntos, las relaciones laborales en la administración pública (La República, 2013).

John Lapa (2017), quien entonces presidiera la COODE ${ }^{\mathbf{2 1}}$, asume la presidencia del CNL, órgano de confluencia de las organizaciones estudiantiles que se manifestaran el 4 de julio contra las condiciones en las que se aprobaba la nueva ley:

La UNFV tuvo como organización matriz del movimiento gremial estudiantil independiente democrático a la COODE. Tal fue así que la reconocieron como un gremio a nivel nacional por lo cual nosotros participamos dentro de las asambleas del comité de lucha con el voto gremial como si la COODE fuese la federación, motivo por el cual yo soy elegido el presidente del comité de lucha.

Seis días después, miembros de la ANR, autoridades de las universidades públicas y estudiantes liderados por el entonces rector de la Universidad Nacional Mayor de San Marcos (UNMSM), Pedro Cotillo, salen a manifestarse en oposición a la propuesta de modificación de la ley universitaria por considerar que vulneraría su autonomía (Defensoría del Pueblo, 2013, p. 83).

El Comité Nacional de Lucha, había hecho público su desafecto hacia la Asamblea Nacional de Rectores, instancia superior de supervisión

21. Coordinadora Democrática Estudiantil 
y licenciamiento para la creación de nuevas universidades en el país, por el manejo poco transparente de su gestión. A propósito, Cuadros, Díaz, Motta, Rodríguez, Zegarra, (2008) citado por el Tribunal Constitucional (2010) sostienen en sentencia, acerca de la labor de la ANR:

La aplicación de la autonomía universitaria en el Perú ha asumido un carácter muy peculiar desde la dación de la actual ley universitaria en 1983, donde el estado dejó de lado su atribución normativa, coordinadora y de exigencia de calidad respecto a la actividad universitaria, encomendando dicha función a la Asamblea Nacional de Rectores, entidad que al estar integrada por los Rectores de las mismas universidades, no ha podido ser suficientemente autoexigente con ellas mismas, para alcanzar niveles de calidad acordes al desarrollo sostenible que necesita nuestro país (p. 54).

Para Mercedes Romero (2017), representante de Vanguardia Villarrealina en el consejo de facultad de Derecho y Ciencias Políticas en el año 2014, la organización por el archivamiento fue impulsada por organizaciones estudiantiles de la macro región sur. Sin embargo, después de muchos años se reactiva la organización en Lima.

En el año 2013 inicia el proceso de la ley universitaria, [que] se encontraba aún en pre-dictamen en la comisión de educación y de alguna forma eso motivó o mejor dicho, generaron las condiciones para que eso se organizara, siendo que los que impulsaron de alguna forma el tema de debate, fueron estudiantes de provincia del sur, la macro sur que en esos tiempos, aún recuerdo, se estaba formando, porque en Lima no había una organización que pueda centralizar una propuesta de debate a lo que se estaba planteando en el congreso [....] Posteriormente se ve la necesidad de la organización a nivel de Lima, por eso se vuelve a consolidar lo que es el Comité Interuniversitario de Estudiantes de Lima (CIEL).

La marcha del 4 de julio fue un hito para medir fuerzas, determinar las posibilidades y limitaciones del movimiento. De hecho, después de esta, se establece un quiebre determinante del movimiento bajo tres posiciones: la primera propuesta por el CNL en no dar marcha atrás con la postura del archivamiento de los dictámenes de la ley universitaria, demandando la reapertura del debate para elaborar desde el principio una nueva ley universitaria (CNL, 2014). La segunda, promovida por la Federación Universitaria de la Pontificia Universidad Católica del Perú (FEPUCP) y la Federación de Estudiantes de la Universidad Agraria (FEUA) que postulaba la modificatoria de algunos de sus artículos, rescatando la 
ley original. La tercera, planteada por la Federación de Estudiantes del Perú que promovía el archivamiento con una propuesta de ley alternativa para su aprobación (FEP, 2013).

El movimiento mismo en la medida que iba avanzado el gobierno se veían algunas vacilaciones, se cambió la consigna de archivamiento por modificatoria, otros por bueno decir: "hay cosas buenas y cosas malas, bueno ya no podemos hacer nada, que avance como está, hay que golpear a la corrupción". Tenemos a la federación de la PUCP, algunos estudiantes de la facultad de psicología que decían: "Está bien, la ley es lo mejor que nos ha podido pasar" y la historia nos da la razón que esa ley universitaria como dijimos en su momento no soluciona nada... (Lapa, J., 2017).

Es cierto que la nueva ley adoptó el voto universal y directo que proponían ciertas federaciones universitarias, pero sigo siendo ponderado o censitario con respecto a cada estamento: docentes y estudiante. La ley dice en su artículo 66: "A los docentes ordinarios les corresponde dos tercios (2/3) de la votación; A los estudiantes matriculados les corresponde un tercio (1/3) de la votación" (Congreso de la República, 2014. p.10).

Cabe acotar que el CNL fue un organismo de alcance nacional que se propuso disputar la dirección del movimiento a la Federación de Estudiantes del Perú por considerar que su directiva no contaba con representatividad a pesar de ser el órgano gremial histórico de alcance nacional. Hay quienes postulan que la unidad del movimiento es importante, es una conclusión algo obvia, pero ¿Cómo lograrla en base a consensos? Al respecto Camila Vallejo, ex-dirigenta del movimiento estudiantil chileno, refiere en entrevista con Hernan Ouviña (2012):

Hay que aprovechar esta instancia y tener iniciativa política también. Lo que se espera es generar el espacio, que en el fondo constituye una oportunidad para el movimiento, y para eso se necesitan ciertas garantías: primero, que se mantenga esta unidad del movimiento que es a lo que todos apuestan. La gente en la calle dice que lo importante, más allá de las reivindicaciones particulares, es que se mantenga unido el movimiento, y mucha gente dice que ya hemos ganado demasiado con este proceso. Es como engendrar, como un embarazo. Estamos desesperados por ver que salga a luz, pero esto recién se está engendrando (p.16).

Yhormil Rojas (2017), estudiante de Ciencias Políticas y miembro de Vanguardia Villarrealina recuerda esta disputa: 
Se volvió a consolidar la formación del Comité Nacional de Lucha [por] que Patria Roja estaba dirigiendo la FEP, se oponía totalmente, como siempre oportunistamente quieren dirigir el movimiento estudiantil, pero en la práctica sabemos cómo está la FEP, no representa a nadie, como organismo se respeta porque tiene una historia y es propia de los estudiantes y ha sido capturado por ese partido.

Independientemente de cuál fuera la posición más acertada al respecto del contexto, en la práctica el movimiento se fracturó, perdiendo protagonismo ante una oportunidad única de reforma en base a consensos, sobretodo, con una percepción de divisionismo y deslealtad frente a los principios del Comité Nacional de Lucha (CNL). La tarea, en este sentido, es cómo dar unidad y coherencia a un movimiento, por definición, plural y diverso; afectado al mismo tiempo por una serie de tensiones entre identidades, estrategias y diagnósticos divergentes. (Vallejo, citado por Ouviña, 2012).

Además, hay un reacomodo de actores y sube a escena la aún poderosa asociación de rectores que promovía el archivamiento de la ley, no en razón de las necesidades e intereses estudiantiles, ni por mejoras salariales de docentes o en busca de la excelencia en la calidad de la educación; sino utilizando, fuera de contexto y adarga al brazo, la autonomía universitaria para evitar que un reorganizado ente suprauniversitario supervise las finanzas y la administración de las universidades que eran dirigidos por ellos mismos durante la existencia de la ANR. Es decir, teniendo la intención de seguir siendo juez y parte.

Curiosamente son los rectores delas universidades más importantes a nivel nacional y en su mayoría de universidades públicas los que repotencian la demanda de archivamiento en paralelo a un debilitado movimiento estudiantil, dividido en sus estrategias y propósitos.

Si bien la COODE en Villarreal tuvo un rol destacado en torno a la postura por el archivamiento de la ley, fortalecida principalmente con la confluencia de actores externos a la universidad, la movilización de recursos y un reducido grupo de estudiantes, se limitaba al espacio de acción que tenían las organizaciones adscritas a la COODE desde sus orígenes, principalmente al local central que abarca las cuatro facultades mencionados al principio y algunas especialidades como Psicología o Economía en otros locales, con el escollo de no contar con el respaldo de la mayoría de estudiantes indiferentes a tal situación. Contrario es lo que sucede años después en 2016 donde el local central sigue siendo el epicentro de la acción colectiva que se propaga a espacios que antes no 
estuvieron articulados al propósito inicial, el archivamiento, pero eso lo veremos más adelante. 


\section{RÉQUIEM PARA UN NUEVO ESCENARIO (2014- 2015): LA ADECUACIÓN DE LA LEY EN VILLARREAL}

Tras este intenso debate, propuestas legislativas alternativas, modificatorias y medidas cautelares para el archivamiento del proyecto de ley, tanto por quienes defendían la gratuidad de la enseñanza, como por quienes defendían la "autonomía" del gobierno universitario. El 9 de julio del 2014 fue aprobada definitivamente la ley universitaria $\mathrm{N}^{\circ} 30220$, reemplazando a la N 23733 que data del año 1983 (Congreso de la República, 2014).

Sin embargo, el proceso de adecuación no sería tan simple. La controversia arribó hasta el Tribunal Constitucional (TC), máxima instancia judicial de la nación para resolver lo que entre las partes no pudo ser resuelto. EI TC falla declarando infundada las demandas de inconstitucionalidad contra la ley que sus detractores argumentaban (Tribunal Constitucional, Pleno Jurisdiccional, Expedientes 0014-2014P1/TC, 0016-2014-PI/TC, 0019-2014-P1/TC y 0007-2015-PI/TC, 2015).

Mientras tanto, el máximo y novísimo ente supervisor de la educación superior creado por disposición de la nueva ley, la SUNEDU, había asumido funciones sucediendo a la ANR, fiscalizando que las universidades de todo el país cumplieran con las primeras medidas de adecuación a la ley y que después fuera ratificada por la sentencia del TC.

Aprobada la ley, la misma disponía automáticamente el cese del rector, vicerrectores, decanos y los miembros de asamblea universitaria, consejo universitario y consejo de facultad como primera disposición transitoria. Lo que vendría después sería la conformación de un Comité Electoral Universitario Transitorio y Autónomo (CEUTA), responsable de organizar y convocar a elecciones para conformar una Asamblea Estatutaria. Esta asamblea sería la encargada de redactar un nuevo estatuto conforme a ley que rija como norma hacia futuro los actos de gobierno universitario, vida académica y que al término de sus funciones convocara a elecciones universales para elegir representantes de ambos estamentos (SUNEDU, 2015).

Sin embargo, la realidad superó y distorsionó el guión, primero porque había la firme sospecha de que los miembros del CEUTA, conformada el 21 de julio del 2014, no cumplía con los requisitos preestablecidos dada la poca transparencia en su elección interna, a tal punto, que un día después se reconforma su estructura. Además, su nombramiento fue refrendado con la firma de una autoridad que ya no lo era, el cesado rector José María Viaña, resistiéndose a dejar el cargo. 
Mirsa Canales (2017) entonces estudiante de Derecho y miembro de Vanguardia Villarrealina comenta en otra entrevista:

La ley establecía ciertos requisitos para que tú seas parte del Comité Electoral (CEUTA)... el comité electoral, los que integran ese comité no cumplían supuestamente con esos requisitos que la ley había establecido y nos adjuntan documentos que aparentemente los sustentaban, como que el récord de los profesores que eran más antiguos, los alumnos que tenían mejores ponderados que no condecían con los que estaban integrando ese comité, una serie de documentos que sustentaban ello [...] y por otro lado nos llegaban otros correos donde nos decían, tales son los profesores que cumplen.

Mirsa Canales (2017) agrega:

Con el profesor Manuel Arana nos entrevistamos y él estaba ya haciendo otra lista con una profesora de humanidades [...], ellos estaban haciendo su lista aparte porque decían que estos profesores, que estaban postulando tenían muchos conflictos de interés [...] y que en realidad había otro comité electoral y que era el que cumplía los requisitos, que estaba organizando sus elecciones y ellos dos se disputaban, obviamente el que era el comité de Viaña [...] el que era entre comillas el oficial, el que la ONPE había reconocido, es más pedimos esa información por transparencia a la ONPE, pero lo pedimos y nos llegó la resolución de la ONPE donde nos decían que ellos no podían pronunciarse sobre eso porque la universidad era autónoma y si la universidad decía que ellos eran ellos tenían que haber sido. Bajo ese contexto e indicios y con sus antecedentes creíamos que efectivamente no cumplían los requisitos. La información nunca se publicó, nunca se hizo de conocimiento, nunca se dijo ellos son los más antiguos según tal resolución o tales documentos y las elecciones eran no transparentes porque no nos dejaron inscribir".

En esta segunda etapa, es plausible la articulación de alianzas con grupos de presión estamental docente. Tal confluencia se reproduce en la comunidad universitaria con fines particularmente institucionales y bajo el contexto de adecuación, habiendo un viraje en el objetivo inicial. Ya no era archivar la ley, ahora era participar del proceso transitorio a través de su asamblea estatutaria. Este nuevo marco normativo permitiría reglamentar derechos que los primeros actores, creían, no habían sido establecidos por el movimiento en el exterior.

Según el Art. 72 de la ley universitaria №30220, El Organismo 
Nacional de Procesos Electorales (ONPE) garantiza la transparencia del proceso electoral y participa brindando asesoría y asistencia técnica (Congreso de la República, 2014), labor que no pudo ni quiso desempeñar a cabalidad a causa de la autonomía universitaria.

Mercedes Romero (2017), miembro también de la Comisión Legal en el año 2016 comenta:

Al principio pues hubo un desacato a la norma por parte de las autoridades porque ellos de alguna forma sintieron que la autonomía se vería vulnerada. Sin embargo continuaron, el rector continuó dentro de sus funciones, no cesó igual que los decanos no cesaron tampoco, continuaron sus periodos hasta donde habían sido elegidos porque en la Villarreal en el 2014 termina el periodo de los decanos que fueron elegidos en el 2011. Una vez que cesan los decanos, el rector continúa con sus funciones. En el año 2015 continúa el proceso de adecuación con comisiones de gobierno. Aún continuaba ejerciendo sus funciones el rector que tuvo mucha injerencia en el proceso de adecuación que era la Asamblea Estatutaria. Entonces hubo mucha injerencia por parte de las autoridades que desencadenó con lo que ocurrió en el año 2016 que es el desconocimiento de los decanos ilegales.

Es así como, el CEUTA conformado, convoca a elecciones para elegir los miembros de la asamblea estatutaria para el 3 de noviembre del 2014. Las organizaciones que en una primera etapa apostaban por el archivamiento, trasladan la acción de disputa externa del movimiento hacia adentro e inician una serie de acciones ante una nueva situación, la adecuación de la ley en Villarreal. El 17 de octubre fue la fecha límite para inscribir a las listas que participarían en la elección de los miembros de la asamblea estatutaria. Ante la imperiosa necesidad de intervenir en un nuevo proceso, deciden modificar la posición anterior a la aprobación de la ley y participar, casi por unanimidad del proceso electoral, tratando de conformar una lista de candidatos estudiantiles independientes. Sin embargo, se les impide el ingreso a las oficinas del comité electoral minutos antes del cierre de la inscripción, ubicado en el local de la facultad de Odontología.

Denis Galindo (2017), egresado de la facultad de educación y miembro de Rumi Maqui lo recuerda así:

Formamos una fuerza que por primera vez se había hecho en ese entonces. Logramos hacer nuestra lista, a pesar de que Sociales no definía su posición todavía, Rumi Maqui y Vanguardia con los 
compañeros de la COODE pusimos las bases para poder concretizar eso y gracias a las fuerzas que reunimos, se pudo llegar a hacer una lista. Pero, por más que tú hagas, tu lista los de arriba ya tiene todo planeado [...] ya tenían su ganador. ¿Qué hicieron con nuestra lista?, no quisieron aceptar nuestra lista. Es por eso que compañeros de Confluencia dicen: ya no nos dejaron, vamos para el voto viciado [...] había un discurso de voto viciado o anforazo.

El anforazo 22 no pasó de una gresca entre los estudiantes organizados y miembros del Comando Universitaria Aprista (CUA) para ejecutar la acción. Hay opiniones encontradas que evalúan su fracaso. Quienes creyeron que ya se manifestaban las pugnas internas entre los voceros de la COODE y el resto de las organizaciones y; quienes a su vez apreciaron una mala organización de la medida de fuerza.

Al respecto Darío Vílchez (2017), vocero de la $\operatorname{COODE}^{\mathbf{2 3}}$, miembro de Transparencia y egresado de psicología lo manifiesta así:

Creo que no hubo coordinaciones exactas porque en ese tiempo estaban con la disputa de si le pasamos la voz a la COODE, porque tiene que estar en esas acciones. No había cierta fuerza de decir todos unificarnos, vayamos con fuerza. Solamente hay que hacerlo los compañeros, no había coordinaciones con COODE [...] Era como hacer el anforazo, pero no la presencia de la COODE, nosotros no nos sentíamos tan identificados porque no nos tomaron en cuenta, no sabíamos cómo actuar, apoyamos sí, pero hasta cierto punto, las cosas se hacen bien, las cuestiones tácticas hay que hacerlas bien.

Este fue también un evento de ruptura de la organización Sociales Independiente que acababa su gestión en el consejo de facultad y empezaría de desaparecer como tal, dando paso a que sus miembros se integraban, en otra coyuntura, a la conformación de nuevas organizaciones paralelas u opuestas a la COODE.

22. Entendido como: medida de fuerza para desconocer un proceso electoral que se cree fraudulento.

23. Coordinadora Democrática Estudiantil. 
Varias compañeras de Sociales se fueron disgustadas. Recuerdo que hubo una disputa después de todo eso, hubo un cisma después de todo eso, sobre todo para Sociales..." (Vilchez, D., 2017) "... En verdad no logramos nada, nos perjudicamos en vez de cumplir el objetivo, la compañera Dessire [...] se siente disgustada, la compañera Mercedes, a raíz de eso dijeron: "tú propones..." y eso es una crítica que hay que reconocer [...] haber apoyado la propuesta inicial del anforazo y luego echarse para atrás y eso provocó que la compañera Dessire y la compañera Meche dijeran: "con ustedes hasta aquí nomás (Cotrina, J., 2017).

Luego de este incidente, algunos de los estudiantes entre los que estaba Mirsa Canales se dirigieron al despacho del congresista Daniel Mora, artífice de la ley universitaria a pedir apoyo ante las irregularidades en el proceso electoral.

Después de esa situación [...] fuimos a hablar con Mora y le dijimos las irregularidades que habían en la universidad, que no se había dado el proceso de adecuación de manera regular, que todo estaba oculto, que no hay transparencia en la información, de que el tema del $A P R A^{\mathbf{2 4}}$ en la universidad, que siempre lo utilizaban como un anexo del APRA, del partido aprista y bueno, él nos dijo que la ley trataba de atacar esos temas, el tema de corrupción, por eso estaba la SUNEDU ${ }^{25}$, que se sentía de brazos cruzados, que no recibía el apoyo (Canales, miembro del Comité Legal del Movimiento estudiantil de la UNFV. Grupo focal, 2017).

Con ello acababa el año 2014. Se instala y se reconoce el CEUTA ${ }^{\mathbf{2 6}}$ conformado irregularmente con la venia de un rector que ya no debía ejercer el cargo, con serias observaciones en el proceso mismo de sufragio y con la inminente posibilidad de que estas observaciones tuvieran consecuencias a largo plazo. La instalada Asamblea Universitaria inicia su trabajo para redactar el estatuto en el año 2015 y acabada su labor convoca a elecciones universales el 23 de febrero del mismo año, estableciendo un cronograma electoral el 24 de julio para elegir rector

\footnotetext{
24. Alianza Popular Revolucionaria Americana.
}

25. La Superintendencia Nacional de Educación Superior Universitaria (SUNEDU) es un organismo técnico especializado adscrito al Ministerio de Educación del Perú.

26. El Comité. Electoral Universitario Transitorio y Autónomo se encarga de organizar, conducir y controlar los procesos electorales de los órganos de gobierno de la Universidad Nacional Federico Villarreal. 
y vicerrectores, miembros de la asamblea y consejo universitario (UNFV, 2017 c) y en elecciones complementarias, decanos y miembros del consejo por facultad.

El año 2015 se convirtió en un año de total dispersión de la organización estudiantil en Villarreal, el desgaste y las divisiones producto de las últimas acciones lo debilitan, sumado a la desconfianza y división en un proceso de adecuación a la nueva ley universitaria. Sin embargo, en el año 2016 la irresponsabilidad de José María Viaña y la vicerrectora, Nancy Oliveros, les cobraría la factura, pero sobre todo en gran medida al perfil del estudiante que aún permanecía indiferente después de dos años de aprobada la ley.

Hasta aquí algunas conclusiones preliminares. Con respecto a las formas de organización, los Grupos Estudiantiles en el Cogobierno dieron un primer viraje en su objetivo, pasaron del archivamiento a la participación de las elecciones para asamblea estatutaria, encontrando una oportunidad para tener influencia en la nueva normatividad institucional. Sin embargo, cuando se vieron superados por el control de los órganos electorales, recurrieron a modos no institucionales de presión, es decir, medidas de fuerza. Melucci (1998) describe este fenómeno así: "la violencia colectiva se manifiesta cada vez que existe un empuje de grupos excluidos que intentan entrar en el sistema político o bien cuando grupos ya representados no quieren perder los privilegios que gozan" (p. 35).

Habiendo esta posibilidad de apertura democrática para la participación es que nos preguntamos: ¿Este movimiento niega o expresa su antagonismo de manera sistémica? o ¿Solo demanda su inclusión en un sistema institucionalizado de beneficios? (Melucci, 1999).

¿Este movimiento niega o expresa su antagonismo de manera sistémica? o ¿Solo demanda su inclusión en un sistema institucionalizado de beneficios? (Melucci, 1999). 


\section{DE LA SUBORDINACIÓN A LA INSUBORDINACIÓN: RECUPERANDO LA UNIVERSIDAD PÚBLICA (2016)}

En 31 de diciembre del 2015 vencía el plazo para adecuar completamente a las universidades de todo el país a un nuevo régimen universitario (SUNEDU, 2015). Pero la universidad había elegido rectores y demás autoridades por facultad con observaciones hechas por SUNEDU durante el proceso. El enquistamiento en el poder es ya insostenible y deriva en crisis institucional. José María Viaña deja a disposición su cargo como rector y nombra a Nancy Oliveras como rectora interina.

Ante esta situación, estudiantes que se insertaban al proceso en enero y los disconformes con el accionar de la $\mathrm{COODE}^{\mathbf{2 7}}$ en etapas pasados forman el denominado Frente de Estudiantes Independientes (FEI) en paralelo. En medio de sus pugnas deciden ambas organizaciones realizar la toma del Anexo $8^{\mathbf{2 8}}$ como medida de fuerza para presionar a las autoridades a cumplir la ley.

Claudia Palacios (2017), estudiante de Biología y entonces presidenta del Centro Federado de Ciencias Naturales y Matemáticas recuerda la toma de enero así:

Fue muy raro porque el mismo día de la toma nos habíamos concentrado en Campo de Marte, era lo que habíamos acordado y nos llega el documento de que el señor José María Viaña había dejado vacante su cargo, sin embargo dicho documento era firmado por el secretario general de ese entonces y no por el mismo rector, por lo que en la asamblea con las personas que estaban presentes se vuelve a decidir si es que se realizaría o no la toma. Se empieza a dudar. El compañero Yhormil, decía que era un engaño más y que no serviría la medida, entonces se somete a la votación. Particularmente yo voté para que no se realizara ya que no había estado en alguna toma antes y tenía un poco de miedo, pero al final por votación se decidió que sí y aun así por decisión de asamblea y con voto de la mayoría yo asistí a la toma. Nos reunimos en el local de la facultad de psicología, en el lugar donde se concentra el consejo de estudiantes de facultad, nos metimos ahí, algunos que habían acordado con estar dentro se fueron, comenzábamos a dudar y los guardias afuera decían: "¿A qué hora lo van a tomar?", porque al parecer ya sabían que lo íbamos a tomar. Entonces se complicaba más la cosa, pero al final acordamos,

27. La Coordinadora Democrática Estudiantil es una organización de Frente Único que aglutina estudiantes de diversas facultades y anexos de la Universidad Nacional Federico Villarreal.

28. El Anexo 8 es el predio de la Villarreal donde funciona la facultad de Psicología. 
y realmente la llegamos a tomar, les pedimos a los guardias y al administrador del local que se retiren. Los que estábamos dentro del local algunos estábamos nerviosos por el tema de las sanciones disciplinarias, pero si las vemos desde contexto legal no había rector entonces no se podían tomar acciones en ese momento, pero poco se entendía de ello, y no lo entendía en ese momento, recién con la experiencia pude entenderlo, incluso todos llegamos al local y nos metemos al consejo a discutir y el compañero Salgado dijo: "Compañeros, los acuerdos de asamblea se respetan". Estaba algo molesto, entonces decidimos tomarlo. Por otro lado, uno de los guardias que salió en televisión acusándolos de que lo habíamos golpeado y que le queríamos quitar el arma, recuerdo que yo estaba con él invitándolo a retirarse y al momento que se sacaba el chaleco y al sacar su arma me golpeó con ella. Al final se tiró sólo a la puerta, pero imagino que era parte del drama, era su trabajo.

Ante la toma del anexo 8, el 22 de enero del 2016 SUNEDU desconoce las firmas la legalidad de José María Viaña y Nancy Oliveros como rectora interina. Ese mismo día se levanta la medida de fuerza en el anexo 8. El 3 de mayo SUNEDU también declara improcedente el registro de las firmas de decanos, acto administrativo necesario para darle legalidad a las sesiones de consejo de facultad, encargada de expeditar la emisión de los grados y títulos en cada facultad.

El 15 de junio SUNEDU denuncia penalmente a la Asamblea Universitaria por ser conformada irregularmente y emitir actos administrativos que no gozaban de legitimidad. El 21 de junio SUNEDU interpuso 3 multas de 100 unidades impositivas tributarias (UIT) ${ }^{\mathbf{2 9}}$ cada una a la universidad Villarreal que ascendieran a la suma de 1.185 millones de soles por la designación de personal docente en cargos administrativos que ya no se contemplaban en la ley así también a la creación de comisiones de gobierno como instancias distintas a las reguladas en la ley, todas estas refrendadas por el cesado rector a través de la Asamblea Estatutaria (SUNEDU, 2016, p. 1). El 6 de Julio, los estudiantes y egresados de la facultad de Odontología toman su local como medida de fuerza buscando presionar a los decanos a dejar sus cargo, sin los cuales, los egresados no estarían debidamente certificados para ejercer su profesión y si el expedito de su título profesional y grado de bachiller contaba con la firma de los decanos desconocidos legalmente por SUNEDU. Al día siguiente lo hacen los estudiantes y egresados del

29. Es el valor en soles, la moneda nacional, establecido por el Estado para determinar impuestos, infracciones, multas, etc. 
local central, el local de Ciencias Naturales o anexo 16 y durante esa misma semana se suman otras facultades en una revuelta desatada por el estado de crisis institucional en que se encontraba la universidad.

Betty Cabanillas (2018), vocera de Odontología durante la toma de julio de 2016 recuerda las razones así:

Desde mi perspectiva. Fue un tema de los alumnos que eran una base anterior a la mía, ellos estaban ya casi medio año en el proceso del trámite de su bachiller y les dijeron que este demoraría, entonces me decidí involucrarme un poco más, ya estaba en el internado y tenía un poco más de tiempo y me di cuenta realmente que la universidad se encontraba en problemas, sus títulos no iban a valer dado que el rector no regularizaba su situación. Fui a dos plantones con ellos al rectorado como un mes antes del inicio de la toma.

Enzo Valentín, estudiante de Historia y miembro del recientemente creado Centro Federado de Humanidades recuerda este insólito hecho así:

Odontología el primer local que se haya tomado. A pesar de ser el local central un lugar bastante politizado que emana acción, irradia acción a los demás locales, a los demás anexos nos sorprendió bastante porque estos compañeros estaban firmes en la acción que tomaron y también los compañeros que estaban delante, como bien salió la compañera Betty Cabanillas y el compañero Quezada, esos compañeros se llenaron de coraje, uno porque tomar un local no es fácil, es lidiar con compañeros que no quieren que se tomen esas acciones, lidiar con seguridad, lidiar incluso hasta con amenazas que a uno ya de por si nos asusta y obviamente nos generó asombro desde el local central.

El 12 de Julio se da la primera y masiva marcha hacia el local de SUNEDU, cientos de estudiantes de Villarreal se movilizan para exigir sanción a las autoridades por el incumplimiento de la ley y la condonación de la multa.

Este es un evento que desborda la acción colectiva de su lugar habitual y se transforma en movimiento social, siendo un punto de confluencia de quienes participaron de los grupos de representación en el cogobierno en años anteriores, colectivos y estudiantes y egresados que mostraron displicencia en el periodo de debate y aprobación de la nueva ley universitaria. 
Franco Mejía (2017), egresado de la Facultad de Derecho y Ciencias Políticas y miembro de la Comisión Legal, estuvo presente en el diálogo con SUNEDU para encontrar una salida al conflicto. Él afirmó lo siguiente:

En esa oportunidad tuvimos apoyo, yo creo que el único apoyo fue la Defensoría del Pueblo que nos permitía tener reuniones, mesas de trabajo, les conversábamos sobre qué medidas se podía tomar, a quién teníamos que acudir, qué teníamos que hacer y cómo podríamos evitar la intervención policial. La Fiscalía no, de hecho la fiscalía inició investigaciones por las tomas de algunos locales principalmente del rectorado y demás locales, no hubo una buena relación con la fiscalía, de hecho, más bien trataba de intimidarnos para que se dejen las medidas de fuerza y con respecto a la contraloría el discurso era ambiguo, decían que sí, que iban a realizar, iban a entrar a todos los locales a revisar todos los documento contables para ver si habían cumplido con todos los procedimientos, si es que había malversación de fondos, etc. y tenían que emitir un informe a octubre del año pasado. hasta ahora seguimos esperando el informe, y bueno, con todo lo que ha salido del contralor, creo que tiene una explicación bastante lógica.

En el mes de junio del 2017, el contralor de la república, Edgar Alarcón es denunciado por grabar una conversación privada con el ex ministro de economía Alfredo Thorne del gobierno de Pedro Pablo Kuczynski y en el que se escucha una presunta negociación presupuestal de contraloría a cambio de sacar adelante proyectos que estaban observados en su cartera por el ente fiscalizador (RPP, 2017).

Luego vendría una seguidilla de rectores interinos electos por la Asamblea Universitaria, cuestionados por los estudiantes y egresados organizados, que sostenían, entorpecía el proceso de adecuación; lo cual dejaría latente la posible ilegalidad de todo acto administrativo refrendado por las autoridades de la gestión interina. ${ }^{\mathbf{3 0}}$

El 19 de julio, el rectorado de la universidad es tomada exigiendo la renuncia de la Asamblea Estatutaria por creerla ilegal e ilegítima y no garantizar un proceso transitorio ordenado y transparente.

30. Entre los rectores y vicerrectores interinos estuvieron: Jorge Saavedra García (Infogob, 2020 g), Julio Figueroa Gonzales (Infogob, 2020 h), Pedro Amaya Pingo (Infogob, 2020 i), afiliados al Partido Aprista Peruano ante el Jurado Nacional de Elecciones (JNE). 
El 8 de agosto del 2016 se realizó la segunda marcha de los estudiantes de Villarreal hacia el Ministerio Público para exigir se investigue y denuncie a las autoridades que persisten en no dejar sus cargos. La represión en tal marcha fue tan violenta que el estudiante de medicina, David Rivas Espíritu, recibió un proyectil o perdigón durante las protesta exactamente en el ojo izquierdo, a solo unas cuadras de la sede central del Ministerio Público en el centro de Lima.

Nilo Rosas (2017), estudiante de Tecnología Médica ubicado en el local conocido como anexo $16^{31}$ relata una medida de apoyo que sumada a las vigilias se convirtieron en acciones alternativas que los estudiantes practicaron para sumarse a la protesta de manera pacífica, donde no comprometan su integridad física.

Era más la cantidad de alumnas que salían e informaban, o sea acarreando, subían a los buses y contaban lo que ocurría, de esa manera en periodos ya avanzados de la medida de fuerza solicitan dinero para poder solventar los gastos que se tenían que hacer, pero informando a la sociedad cuál era la problemática. Si bien había prensa, no era mucha, entonces también se cumplía mediante se informaba a la sociedad, teníamos la parte de autogestión para poder ayudarnos con respecto a la alimentación porque a veces escaseaban los productos. La prioridad eran los compañeros que estaban dentro de la medida de fuerza. Entonces como responsabilidad y obrando por estas medidas viables se daban estas actividades. Era hermoso ver a los compañeros y compañeras que iban y realizaban este sacrificio porque era ir, salir y hablarle a la gente que muy poco sabía que la Villarreal pasaba por este problema, dar la información y poder llevar algo a los compañeros, esta parte es muy bonita y siempre son anécdotas dignas de recordar.

El 12 de agosto, tras 40 días de toma se levanta la medida con el compromiso de impedir que los representantes sean procesados disciplinariamente por las autoridades, que la Contraloría abriría una auditoría para investigar irregularidades en contratación de bienes y servicios en la universidad durante los últimos tres años (América TV, 2016).

31. El Anexo 16 es uno de los locales de Villarreal donde funcionan las Ciencias de la Salud. 
Días antes de levantar la toma del local central, el busto del líder histórico y fundador del partido aprista peruano, Víctor Raúl Haya de la Torre, ubicado en la puerta de ingreso, desapareció en circunstancias desconocidas (RPP, 2016 b), siendo repuesto en su lugar el busto del verdadero patrono de la universidad, Federico Villarreal. El nuevo busto permanece allí como símbolo de que la universidad fue recuperada, al menos por 40 días, por sus estudiantes y egresados. 


\section{CONCLUSIONES}

La intervención de la ANR a consecuencia del impedimento de elecciones libres en Villarreal en 2010, la conformación de un nuevo organismo estudiantil centralizado como la COODE en este mismo episodio y del FEl en 2016 en la etapa de aprobación y aplicación de la ley universitaria fueron parte de un mismo proceso episódico y disgregado de alianzas y pugnas entre los actores más importantes a nivel nacional y local del movimiento estudiantil. Ha existido en esta breve historia del movimiento una tendencia a la unificación típico de los grupos subalternos descritos por Antonio Gramsci (1934). Advertimos que, a diferencia del movimiento estudiantil de 1918, el del Perú de hoy, carece aún de un espíritu unitario (Mariátegui, 1928) desconectado con las marejadas del contexto nacional, principalmente determinado por la lucha contra la corrupción y las desigualdades sociales a nivel nacional que conecte con nuevas y diversas subjetividades.

Aunque la lectura gramsciana se perfila rigurosamente bajo contextos revolucionarios, es de utilidad, para establecer coordenadas en los procesos movilizadores de la historia social. En este caso bien podríamos afirmar que la reforma universitaria de 2014 representa las características de una revolución pasiva progresiva (Modonessi, 2017), en tanto adquiere algunos elementos reivindicativos de los sectores más radicalizados y subalternos, como el voto universal para la elección de autoridades, pero concibe mecanismos de regulación supra universitarios más estandarizados y jerárquicos para luchar contra la corrupción y afianzar a profundidad la reforma en aspectos como el rol subsidiario del estado en la educación a través de mecanismos regulatorios que la mano invisible del mercado por sí solo no pudo regular, en un modelo neoliberal de veintiséis años ininterrumpidos.

Aunque no hubo consensos programáticos del movimiento respecto a la reforma universitaria para instalar una agenda, Villarreal tuvo una clara participación con liderazgos que se foguearon en pugnas tradicionales del movimiento de cómo conducir la organización. Además, fue un espacio que fue consolidando la experiencia de los estudiantes que ingresaban a la vida política en la universidad y que lograron liderar dentro de ella el proceso de lucha contra la corrupción durante los años 2014 y 2016 hasta hoy. Ya en la etapa de adecuación: "se ponderaron las opciones de negociación que solo al manejo de los recursos, sin dejar de considerarlos como parte de ese convenio entre quienes detentan el poder y los que se movilizan para aprovechar coyunturas y ventajas" (Aranda, 2000, pp. 227 - 228). 
El activismo estudiantil crítico en Villarreal, aunque en sus inicios se reducía a dos locales, tanto el local central como el anexo 8 , ahora se propaga a diversas facultades en un claro ejemplo de que la subalternidad fue fisurada episódicamente gracias al cambio cualitativo del discurso y sus tácticas, frente a la nueva ley en la etapa de adecuación que permitió, durante el desconocimiento de las autoridades suplantadoras, articular alianzas cuantitativamente y cualitativamente mejor organizadas con los estudiantes hasta entonces indecisos por protagonizar la conducción estamental y colegiada de la universidad. En los términos de la reforma de Córdoba, que imagina a la universidad en relación a la sociedad como una república chica dentro de la republica grande, no concibe un corte drástico entre los/as estudiantes y los/as docentes desde el punto de vista de la ciudadanía universitaria. Son todos parte del demos universitario (Kandel, 2005). Las contrareformas posteriores a 1918 han instruido a sus sucesores en que la autonomía no debe ser convertida en dogma o principio absoluto para que en lugar de ministros nos gobiernen profesores igualmente burocratizados y movidos por idénticos intereses. La autonomía es una disposición relativa a los procesos democráticos y a los beneficios que con ella puedan obtenerse en la esfera de la enseñanza y en especial en el de la investigación científica. (Ciria A. y Sanguinetti H., 1962, p. 95).

Se han modificado formas de organización, pasando de la representación en el cogobierno, al gremial/centros federados que busca ampliar, con algunas dificultades, su representación con sustento en la organización de bases estudiantiles. Sin embargo, es necesario reconocer también, el insoslayable aprendizaje que trae conocer el aparato universitario por dentro, lidiando con la gestión administrativa y académica de la universidad a nivel de facultad. Esa experiencia fue vital para darle dirección política y legal al movimiento. Esta cristalización de la acción colectiva a través de su institucionalización, fue oportunamente cesada por la ley y en su remplazo se constituyeron asambleas generales y colegiadas, que buscarían producir estructuras cognoscitivas comunes que permitieron valorar el ambiente y calcular los costos y beneficios de la acción, participando así en el proceso de construcción de una identidad colectiva (Melucci, 1999); algo improbable con tal nivel de alcance y eficiencia en la etapa previa a la adecuación de la ley. 
Tabla 2.

\section{FORMAS DE ORGANIZACIÓN Y ACCIONES HACIA ADENTRO}

\section{$2013-2015$}

Representación en el cogobierno (institucionales)

Coordinación de actividades

(culturales y

académicas)
Vocerías

(no

institucionales)

2016

Comisiones de lucha (no institucionales)

\section{FORMAS DE ORGANIZACIÓN Y} ACCIONES HACIA AFUERA

\section{$2013-2015 \quad 2016$}

Coordinadoras

Articulación con

interuniversitarias organismos

(no institucionales) suprauniversitarios

y autónomas

estatales.

Comités de lucha (no institucionales)

(SUNEDU, Contraloría, Defensoría del y Coordinaciones parlamentarias

Fuente: Elaboración propia.

Tabla 3.

\section{METAS HACIA ADENTRO \\ $2013-2015$ 2016}

Gestionar demandas estudiantiles

Destituir a autoridades ilegales

Participar de la redacción del Nuevo Estatuto

\section{Reorganizar elecciones estatuarias}

\section{METAS HACIA AFUERA}

$2013-2015 \quad 2016$
Archivar la ley
uniiversitaria
Reiniciar el debate parlamentario

Lograr que

SUNEDU

transparente la adecuación a la nueva ley y lograr reconozca los grados y títulos de los egresados

Fuente: Elaboración propia. 
La estrategia de comunicación a través de redes sociales del movimiento se ha renovado haciéndose más eficiente en tanto el nivel y pluralidad en la participación han aumentado. "Ya no se movilizan solo corrientes estudiantiles herederas del clasismo, convencidas de que mediante el diálogo era imposible conseguir alguna reivindicación y que el único medio disponible era la fuerza: huelgas, marchas, ocupaciones de fábricas" (Flores Galindo, 2007 b, p. 455). para combatir un modelo de gestión autoritario, Con esta experiencia se evidencia la movilización de los estudiantes que participan y abarcan tanto el surgimiento de una subjetividad política en relación al contexto en Villarreal en procesos unitarios de acción colectiva, relativamente al margen de las clases sociales hasta la manifestación de acciones eminentemente democráticas (Aranda, 2000, p. 230) denunciando y luchando contra la corrupción como un obstáculo para lograr lo que parece ser en la práctica las nuevas aspiraciones del movimiento, a causa del incremento de la prosperidad generando un aumento en las demandas por el acceso a bienes escasos, muchos de ellos "bienes posicionales" como un ambiente agradable y una buena educación (Aranda, 2000, p. 232) y por qué no decirlo, suscritos a los métodos del clasismo. La subjetivación política del estudiante displicente ha ido ganando autonomía frente a la hegemonía corporativa del estamento docente y las autoridades que controlan la administración universitaria. Ha operado en el sujeto estudiantil real y complejo un momento complementario o vinculado de rebeldía y sumisión (Modonesi, 2010).

Entonces, el de Villarreal es un movimiento dinámico al que ingresan nuevas tendencias, renovando formas de organización institucionales con no institucionalizadas y radicalizando sus medidas de fuerza en momentos en lo que ve perder su poder de negociación colectiva. Por lo tanto creemos que es un movimiento de gestación interna adherido a uno local y nacional, sobre el cual, presumimos, tiene características definidas: participación gremial, sucesos violentos, tendencias redistributivas, pero que no terminan de cuajar a nivel político lo cual no nos permita determinar una meta unitaria o que prioriza una agenda sobre otra, aunque si este presente en algunos de sus actores, por ejemplo: la lucha contra la corrupción sobre la mercantilización de la educación superior o el desfinanciamiento de la educación pública.

Finalmente, en este proceso de conquista paulatina de su autonomía, los estudiantes organizados debieran redirigir sus esfuerzos hacia el gobierno universitario con la misma tenacidad que han destinado para la organización gremial con el fin último de quebrar la hegemonía (Modonesi, 2010) de los intereses partidarios ocultos, visibilizados en tiempo de crisis y sus interlocutores externos que se desempeñan como funcionarios de la universidad u otros ámbitos. Todo ello en el marco de la nueva ley universitaria, promoviendo iniciativas legislativas que se convirtieron en herramientas democráticas e institucionales de gestión universitaria para beneficio común. Por ejemplo, proponemos la paridad estamental en cada 
una de las instancias de gobierno y su participación directa en la ejecución del presupuesto y acceso libre a la información en temas como el bienestar universitario, contratación docente e investigación y la inclusión de actores sociales externos a los procesos de investigación bajo líneas definidas e institucionales para que la legitimidad de la universidad recupere su rumbo. 


\section{BIBLIOGRAFÍA}

América TV (11 de agosto del 2016). Villarreal: Contraloría y Fiscalía ingresaron para auditor universidad. Recuperado de httpww.americatv.com.pe/noticias/actualid ad/contraloria-y-ministerio-publico- auditaran-universidad-federico-villareal- n241951.

Administración de Fondo de Pensiones (2014). Planilla de Declaración y Pago de Aportes Provisionales N 112288254 - Universidad Inca Garcilaso de la Vega.

Aranda Sánchez, José (2000). El Movimiento Estudiantil y la Teoría de los Movimientos Sociales. Convergencia, Revistas de Ciencias Sociales, vol. 7, № 21. Enero - Abril 2000. Universidad Autónoma del Estado de México. Toluca, México.

Asamblea Nacional de Rectores (12 de noviembre del 2010). Declaran en situación de ingobernabilidad a la Universidad Nacional Federico Villarreal y conforman Comisión de Orden y Gestión. [Resolución No 1116 de 2010] DO: El Peruano, Normas Legales 429186

Asociación de Universidades Públicas (2017 a). Elección del Consejo Regional Interuniversitario de Lima y Callao de ASUP. Recuperado de http://asup.edu.pe/ eleccion-del-consejo-regional-interuniversitario-de-lima-y-callao-de-asup/.

Asociación de Universidades Públicas (2017 b). Pronunciamiento: A tres años de la ley universitaria 30220. Recuperado de http://asup.edu.pe/pronunciamiento-asup- $181017 /$.

Casas Sulca, Frank (2012). La regulación regulada: el sentido de la expansión universitaria en el Perú desde el CONAFU. Revista de la educación superior. Vol. XLI (3), No. 163. Julio - Septiembre de 2012, México. D.F. pp. 141-157.

Centro de Estudios y Documentación Internacionales de Barcelona - CIDOB (2016). Biografía de Líderes Políticos: Alan García Pérez. Recuperado de https://www. cidob.org/biografias_lideres_politicos/america_del_sur/peru/alan_garcia_ perez. 
Ciria, A. y Sanguinetti H. (1963). Universidad y Estudiantes - Testimonio Juvenil. Buenos Aires. Ediciones Depalma.

Comisión de la Verdad y Reconciliación (2003 a). Las Desapariciones de los estudiantes de la Universidad Nacional del Centro (1990-1992). Recuperado de http:// www.cverdad.org.pe.

Comisión de la Verdad y Reconciliación (2003b). El asesinato de Orestes Rodríguez Campos (1990) Recuperado de http://www.cverdad.org.pe.

Comisión de la Verdad y Reconciliación (2003 c). Las ejecuciones extrajudiciales de universitarios de la Cantuta (1992). Recuperado de http://www.cverdad.org.pe.

Comité Nacional de Lucha [Comité Nacional de Lucha] (22 de junio del 2014). Jornada Nacional de Lucha Estudiantil [Estado de Facebook] Recuperado de https://www.facebook.com/Comit\%C3\%A9-Nacional-de-Lucha-1417074081849834/

Congreso de la República del Perú (2017). Expediente Virtual Parlamentario de la Ley Universitaria $N^{\circ}$ 30220. Recuperado de http://www2.congreso.gob.pe.

Congreso de la República del Perú (2017). Expediente Virtual Parlamentario de la Ley Universitaria N²9971. Recuperado de http://www2.congreso.gob.pe.

Congreso de la República del Perú (9 de diciembre de 1983). Ley Universitaria [Ley 23733 de 1983]. DO: El Peruano, Normas Legales s/n.

Congreso de la República del Perú (9 de julio del 2014). Ley Universitaria [Ley 30220 de 2014]. DO: El Peruano, Normas Legales Nº 527213.

Congreso de la República (s.f.). Recuperado de http://www4.congreso.gob.pe/museo/presidentes/276.Ramiro-Priale-Priale 1964.pdf. 
Corresponsales.pe (22 de febrero del 2014). Alan García habla sobre el dictamen de la nueva ley universitaria [Archivo de Vídeo] Recuperado de https://youtu.be/ P7nxTESXhHM

Cuadros Blas, Jorge; Díaz Garay, Bertha; Motta Ferreccio, Aldo; Zegarra Pellanne, Jorge (2008). Informe sobre el Sistema de Educación Superior Universitaria del Perú (Proyecto ALFA N DCI-ALA-2008-42 "Aseguramiento de la Calidad: Políticas Públicas y Gestión Universitaria"). Recuperado de http://www2.congreso. gob.pe.

Cuenca, Ricardo (2015). La educación universitaria en el Perú: democracia, expansión y desigualdades. Ed. Lima, IEP.

Correo (9 de agosto del 2016). UNFV: alumno que recibió proyectil podría perder la vista del ojo izquierdo. Recuperado de https://diariocorreo.pe/peru/universitario-que-recibio-proyectil-en-protesta-podria-perder-vista-del-ojo-izquierdo-video-690172/.

El Comercio (29 de junio del 2014). Daniel Mora: “Ley Universitaria acabará con las universidades chicha". El Comercio. Recuperado de https://elcomercio. pe/politica/congreso/mora-leyuniversitaria-acabara-universidades- chicha-335443.

Defensoría del Pueblo (2013). Reporte mensual de conflictos sociales $N^{\circ} 133$, julio 2013, pág. 83.

Federación de Estudiantes del Perú (13 de febrero del 2013). Anteproyecto de la Nueva Ley Universitaria. Lima, FEP.

Flick, Uwe (2015). El diseño de Investigación Cualitativa, Madrid, Ediciones Morata.

Flores Galindo, Alberto (2007). Obras Completos VI. La Tradición Autoritaria. Lima: Casa de Estudios del Socialismo. pp. 454-462. 
Gramsci, Antonio. (1934). Cuadernos de la Cárcel, Tomo VI, cuaderno NXXV. México D.F. Benemérita Universidad de Puebla.

Haya de la Torre, Víctor Raúl (1985). El Antimperialismo y el APRA. Sexta Edición. Santiago de Chile.

Infogob (2018 a). Recuperado de http://www.infogob.com.pe/Politico/Ficha Politico/ramiro-priale-priale_procesos-electorales_PaZpBM05JG0c6+@0EIOxM $A==$.

Infogob (2018b). Recuperado de http://www.infogob.com.pe/Politico/FichaPolitico/javier-pulgarvidal_procesos-electorales_eadgzp+tmecc6+@0EIOxM A==.

Infogob (2018c). Recuperado de http://www.infogob.com.pe/Politico/Ficha Politico/alan-gabriel-ludwig-garcia-perez_historial-partidario_Ea3WWRWY3Vs=.

Infogob (2018d). Recuperado de http://www.infogob.com.pe/Politico/Ficha Politico/mercedes-cabanillas-bustamante_historial-partidario_3GZGn8GOV@0=.

Infogob (2018e). Recuperado de http://www.infogob.com.pe/Politico/FichanPolitico/orestes-rodriguez-campos_historial-partidario_XVqLMK3C60wc6+@0EIOxM A==.

Infogob (2018f). Recuperado de http://www.infogob.com.pe/Politico/Ficha Politico/juan-oswaldo-alfaro- bernedo_historial-partidario_1 $\mathrm{NtH}+\mathrm{HhaZJ8=.}$

Infogob (2020g). Recuperado de https://infogob.jne.gob.pe/Politico/FichaPolitico/jorge-alejandro-saavedra-garcia_historial-partidario_qvNoFBlijd0c6+@0EIOxMA==NB.

Infogob (2020h). Recuperado de https://infogob.jne.gob.pe/Politico/FichaPolitico/ julio-lorenzo-figueroa-gonzales_historial-partidario_Va6k+IU8S60=6l.

Infogob (2020i). Recuperado de https://infogob.jne.gob.pe/Politico/FichaPolitico/pedro-manuel-amaya-pingo_historial-partidario_HvU4KQP7cXQc6+@0EIOxMA==UQ. 
Jara Hollyday, Oscar (2018). La sistematización de experiencias: práctica y teoría para otros mundos políticos - 1ed. Bogotá, Centro Internacional de Educación y Desarrollo Humano - CINDE.

Kandel, Victoria (2005) Formas de gobierno en la universidad pública: reflexiones sobre la colegiación y la democracia. Buenos Aires, Consejo Latinoamericano de Ciencias Sociales.

La República (5 de julio del 2013). Día de furia por protestas de estatales y universitario. Recuperado de https://larepublica.pe/archivo/722916-dia- de-furia-porprotestas-de-estatales-y- universitarios-fotos.

Manrique, Nelson. (2009). $<<j$ Usted fue aprista! >>: bases para una historia crítica del APRA. Lima: Fondo Editorial de la Pontificia Universidad Católica del Perú.

Melucci, Alberto (1999) Acción Colectiva, Vida Cotidiana y Democracia. México: El Colegio de México, Centro de Estudios Sociológicos.

Modonessi, Máximo. (2010). Subalternidad, antagonismo, autonomía. Marxismo y subjetivación política. Buenos Aires: Consejo Latinoamericano de Ciencias Sociales; Prometeo Libros.

Modonessi, Máximo. (2017) Revoluciones Pasivas en América. Ciudad de México: Universidad Autónoma Metropolitana. Editorial Ítaca.

Morín, Edgar (1984). La Conciencia de la Ciencia. Barcelona: Editorial Anthropos.

Oficina Central de Relaciones Nacionales e Internacionales y Cooperación Técnica (5 de agosto del 2014). Convenio de Cooperación Interinstitucional [Oficio $\mathrm{N}^{\circ}$ 231-2014-OCRNICT-UNFV]. DO: Resolución R. Nº 7320-2015-CU-UNFV.

Ouviña, Hernán (2012). Somos la generación que perdió el miedo: Entrevista a Camila Vallejo Dowling. Observatorio Social de América Latina, Volumen Nº31, (13-20). Recuperado de http://biblioteca.clacso.edu.ar/clacso/osal/20120417105250/ OSAL31.pdf. 
Perú 21 (18 de octubre del 2014). ASUP: Rectores forman nueva asociación tras $\quad$ I a desactivación de la ANR. Recuperado De: https://peru21.pe/politica/asup-rectores- forman-nueva-asociacion-desactivacion- anr-191212.

Pontificia Universidad Católica del Perú. (1999). Javier Pulgar Vidal: Geógrafo del Perú. Cuadernos del Archivo de la Universidad. Recuperado de http://repositorio. pucp.edu.pe/index/handle/123456789/28679.

Raschke, Joachim. (1994) Sobre el concepto de movimientos social. Revista Zona Abierta, Volumen 69,121.

Reyna, Carlos (2000) La Anunciación de Fujimori, 1985 - 1990. Lima: DESCO.

RPP (17 de mayo del 2014). Daniel Mora: ANR busca proteger a rector de Universidad Inca Garcilaso de la Vega. Recuperado de http://rpp.pe/politica/actualidad/daniel- mora-anr-busca-proteger-a-rector-de-universidad-inca-garcilaso-de-la-vega-noticia-692718.

RPP (8 de agosto del 2016 a). Estudiantes de la universidad Villarreal y policía se enfrentaron en el cercado de Lima. RPP. Recuperado de https://lima/actualidad/universitarios-y-policía-se-enfrentaron-en-elcercado-de-lima-noticia-985672.

RPP (12 de agosto del 2016 b). Denuncian robo de busto de Haya de la Torre en sede de la UNFV. Recuperado de http://rpp.pe/lima/policiales- crimenes/denuncian-robo-de-busto-de- haya-de-la-torre-en-sede-de-la-unfv- noticia-986702.

RPP (3 de Julio del 2017). Estas son las cuatro razones por las que el contralor puede servacado. Recuperado de: /rpp.pe/politica/actualidad/estas-son-las- cuatrorazones-por-las-que-el-contralor- puede-ser-vacado-noticia-1060652.

Saforcada, Fernanda; Atairo, Daniela; Trotta, Lucía; Rodríguez Golisano, Aldana (2019). Tendencias de privatización y mercantilización de la universidad en América Latina: los casos de Argentina, Chile, Perú y República Dominicana. 1a edición. Ciudad Autónoma de Buenos Aires: IEC - CONADU; San José de Costa Rica: Internacional de la Educación-IE. 
Santos, B. d. S. (2001). Los nuevos movimientos sociales. Observatorio Social de América Latina, Volumen N5, (177-184). Recuperado de http://www.boaventuradesousasantos.pt/media/pdfs/Los_nuevos_movimientos_sociales_OSAL2001.PDF.

Santos, B. d. S. (2006). La universidad popular del siglo XXI. América. Fondo Editorial de la Facultad de Ciencias Sociales (UNMSM).

Sistema Nacional de Evaluación, Acreditación y Certificación de la Calidad Educativa (2010). Propuesta Del Glosario De Términos Básicos De Evaluación, Acreditación, Y Certificación DeI SINEACE. Lima. SINEACE.

Superintendencia Nacional de Educación Superior (2015). Resolución del Consejo Directivo Nº02-2015-SUNEDU/CD Guía De Adecuación De Gobierno De Las Universidades Públicas Al Amparo De La Primera Disposición Complementaria Transitoria De La Ley N³0220.

Superintendencia Nacional de Educación Superior (2016). Resolución del Consejo Directivo N²22-2016-SUNEDU/CD Declarar que la Universidad Nacional Federico Villarreal incurrió en diversas infracciones tipificadas en el Anexo "Tipificación de Infracciones a la Ley No 30220 - Ley Universitaria del Reglamento de Infracciones y Sanciones de la SUNEDU.

Thompson, Edward (1981).Miseria de la teoría. Barcelona. Editorial Crítica.

Tribunal Constitucional, Pleno Jurisdiccional (17 de julio del 2010). Expedientes

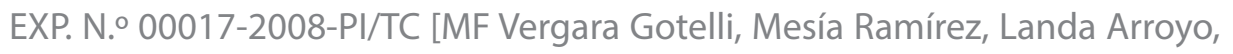
Beaumont Callirgos, Calle Hayen, Eto Cruz, Álvarez Miranda].

Tribunal Constitucional, Pleno Jurisdiccional (10 de noviembre del 2015). Expedientes 0014-2014-P1/TC, 0016-2014-PI/TC, 0019-2014- P1/TC y 0007-2015-PI/TC [MF Urviola Hani, Miranda Canales, Ramos Núñez, Ledesma Narváez, Espinoza Saldaña Barrera]. 
Universidad Nacional Federico Villarreal (15 de mayo del 2014). Marcha en Defensa de la Autonomía Universitaria. Recuperado de http://vrac- unfv.blogspot. pe/2014/05/marcha-en-defensa- de-la-autonomia.html.

Universidad Nacional Federico Villarreal (2017 a). Reseña Histórica. Recuperado de http://www.unfv.edu.pe/site/resena- historica.

Universidad Nacional Federico Villarreal (2017 b). Recuperado de http://web2. unfv.edu.pe/sitio/index.php/transparencia/transparencia-universitaria/ informacion-docente/plana-docente/docentes pregrado/cuerpo-docenteeducacion.

Universidad Nacional Federico Villarreal (2017 c). Resolución Nº 6443-2014-CU-UNFV. Aprobación del cronograma de Elecciones para Representantes Docentes y Estudiantes ante la Asamblea Estatutaria 2014. 


\section{TESTIMONIOS}

Cabanillas, Betty. (16 de abril del 2018). Entrevista individual con Daniel Caravedo (grabación de audio) en Jr. Santa Rosa 360 - Cercado de Lima. Proyecto de Sistematización de Experiencias. Colectivo MITO, Lima.

Canales, Mirsa; Cotrina, Juber; Galindo, Denis y Vélez, Darío. (24 de junio del 2017). Entrevista Grupal con Daniel Caravedo y Alvaro Liendo (grabación de audio) en Jr. Santa Rosa 360 - Cercado de Lima. Proyecto de Sistematización de Experiencias. Colectivo MITO, Lima.

Lapa, John. (22 de junio del 2017). Entrevista individual con Daniel Caravedo (registro audiovisual) en Jr. Inca 260 - Rímac. Proyecto de Sistematización de Experiencias. Colectivo MITO, Lima.

Mejía, Franco. (28 de junio del 2017). Entrevista individual con Daniel Caravedo (registro audiovisual) en Jr. Inca 260 - Rímac. Proyecto de Sistematización de Experiencias. Colectivo MITO, Lima.

Palacios, Claudia. (30 de junio del 2017). Entrevista individual con Daniel Caravedo (registro audiovisual) en Jr. Inca 260 - Rímac. Proyecto de Sistematización de Experiencias. Colectivo MITO, Lima.

Rojas, Yhormil. (1 de julio del 2017). Entrevista individual con Daniel Caravedo (registro audiovisual) en Jr. Inca 260 - Rímac. Proyecto de Sistematización de Experiencias. Colectivo MITO, Lima.

Romero, Mercedes. (26 de junio del 2017). Entrevista individual con Alvaro Liendo (registro audiovisual) en Av. Nicolás de Piérola S/N - Cercado de Lima. Proyecto de Sistematización de Experiencias. Colectivo MITO, Lima.

Rosas, Nilo y Valentín, Enzo. (25 de junio del 2017). Entrevista grupal con Sttefany Ruiz y Daniel Caravedo (grabación en audio) en Jr. Inca 260 Rímac. Proyecto de Sistematización de Experiencias. Colectivo MITO, Lima. 